\title{
Selenium supplementation in the management of thyroid autoimmunity during pregnancy: results of the "SERENA study", a randomized, double-blind, placebo-controlled trial
}

\author{
G. Mantovani ${ }^{1}$ - A. M. Isidori ${ }^{2}$ - C. Moretti ${ }^{3}$ C. Di Dato ${ }^{2} \cdot$ E. Greco ${ }^{4} \cdot$ P. Ciolli ${ }^{5}$ - M. Bonomi ${ }^{6} \cdot$ L. Petrone $^{7}$. \\ A. Fumarola ${ }^{2}$ - G. Campagna ${ }^{2}$ - G. Vannucchi ${ }^{1} \cdot$ S. Di Sante ${ }^{2} \cdot$ C. Pozza ${ }^{2} \cdot$ A. Faggiano ${ }^{8} \cdot$ A. Lenzi ${ }^{2} \cdot$ E. Giannetta $\mathbb{1}^{2}$
}

Received: 25 January 2019 / Accepted: 12 May 2019 / Published online: 25 May 2019

(c) The Author(s) 2019

\begin{abstract}
Purpose Selenium is frequently in nutraceuticals for pregnancy, given its role on fertility and thyroid metabolism. However, most evidence rise from non-controlled studies. We aimed to evaluate the protective effect of selenium against thyroid autoimmunity during and after pregnancy.

Methods A multicenter, randomized, double-blind, placebo-controlled trial was performed and promoted by the Young Italian Endocrinologists Group (EnGioI) - Italian Society of Endocrinology. Forty-five women with thyroiditis in pregnancy were enrolled and randomly assigned to L-selenomethionine (L-Se-Met) $83 \mathrm{mcg} /$ day or placebo (PLB) and evaluated at $10 \pm$ 2 (T1), $36 \pm 2$ weeks of gestation (T2) and 6 months after delivery (postpartum, PP).

Results We measured a significant reduction of autoantibodies after pregnancy in L-Se-Met group [at PP: TgAb 19.86 (11.59-52.60), $p<0.01$; TPOAb 255.00 (79.00-292.00), $p<0.01$ ], and an antibodies titer's rebound in PLB group (TgAb $151.03 \pm 182.9, p<0.01$; TPOAb $441.28 \pm 512.18, p<0.01$ ). A significant increase in selenemia was measured in L-Se-Met group at T2 $(91.33 \pm 25.49 ; p<0.01)$ and PP $(93.55 \pm 23.53 ; p=0.02)$. Two miscarriage occurred in PLB. No differences were found in thyroid volume, echogenicity, quality of life, maternal/fetal complications.

Conclusions SERENA study demonstrated a beneficial effect of L-Se-Met supplementation on autoantibody titer during pregnancy and on postpartum thyroiditis recurrence.
\end{abstract}

Keywords L-selenomethionine $\cdot$ Autoimmune thyroiditis $\cdot$ Maternal complications $\cdot$ Fetal risk

\section{Introduction}

Over the last 30 years, it has become clear that thyroid autoimmunity, including Graves' disease, is correlated with a series of maternal and fetal risks during pregnancy and with

E. Giannetta

elisa.giannetta@uniroma1.it

1 Fondazione IRCCS Ca’ Granda Ospedale Maggiore Policlinico, Endocrine Unit - Department of Clinical Sciences and Community Health, University of Milan, Milan, Italy

2 Department of Experimental Medicine, "Sapienza" University of Rome, Rome, Italy

3 Department of Internal Medicine, "Tor Vergata" University of Rome, Rome, Italy

4 Reproductive Medicine and Biology Center, "European Hospital" female infertility [1-8]. Research has led to different proposals for acting on the target of thyroid autoimmunity. It has been suggested that levothyroxin (LT4) replacement therapy reduces the risk of abortion and preterm birth, although this effect disappears once euthyroidism is reached $[9,10]$.

of Rome, Rome, Italy

5 Department of Gynecological Sciences - Obstetric and Urological Sciences, "Sapienza" University of Rome, Rome, Italy

6 Department of Clinical Sciences and Community Health, University of Milan, Milan, Italy

7 Department of Endocrinology, Careggi University Hospital, Florence, Italy

8 Thyroid and Parathyroid Surgery Unit, Istituto Nazionale per lo Studio e la Cura dei Tumori "Fondazione G. Pascale", IRCCS, Naples, Italy 
Recent years have seen a dramatic rise in food supplements recommended or suggested during pregnancy. There is evidence that selenium supplementation reduces the antibody titer in the course of thyroiditis, improving glandular echogenicity in a sample of male and female patients [11], while women with a history of recurrent pregnancy loss have low blood selenium levels [12]. Furthermore, low selenium levels are associated with an increased prevalence of thyroid disease [13].

Data about the effects of selenium supplementation are sparse and are needed [14-16]. The aim of the present study is to establish if selenium supplementation has any protective effect on thyroid autoimmunity during and after pregnancy.

\section{Subjects and methods}

\section{Study design}

We designed a multicenter, randomized, double-blind, placebo-controlled trial to evaluate the effects of L-selenomethionine (L-Se-Met) supplementation on antibody titer in euthyroid pregnant women with positive antithyroid antibodies. Secondary outcomes included thyroid hormones; thyroid volume and echogenicity; delivery, obstetrical, fetal, and neonatal complications; and healthrelated quality of life (HRQOL). Ten Italian endocrinology and gynecology referral centers took part in the study, for which the Department of Experimental Medicine and Endocrinology, "Sapienza" University of Rome was the coordinating center. The study was promoted and supported by the Young Italian Endocrinologists Group (EnGioI) of the Italian Society of Endocrinology (SIE). The study was approved by Ethical Committee of Policlinico Umberto I Hospital, "Sapienza" University of Rome. All procedures performed in studies involving human participants were in accordance with the ethical standards of the institutional and/or national research committee and with the 1964 Helsinki declaration and its later amendments or comparable ethical standards. After protocol was approved by the institutional review board at each center. Informed consent was obtained from all participants after a full explanation of the purpose and nature of all procedures involved.

\section{Participants}

Women aged between 18 and 45 years who were positive for thyroglobulin antibodies ( $\mathrm{TgAb}$ ) and/or thyroid peroxidase autoantibodies (TPOAb) and who were pregnant (4-8 \pm 2 weeks of gestation) were included in the study. The enrollment period was between November 2011 and November 2016 (end of treatment, January 2018). Serum
TSH was tested at the screening visit (T0) and levothyroxine (LT4) treatment was initiated or adjusted for TSH values above $2.7 \mathrm{mIU} / \mathrm{L}$ [17-19].

The exclusion criteria were as follows: use of corticosteroids, anti-inflammatory drugs, vitamins, food supplements, trace elements, antidepressants/antipsychotics, amiodarone, propanolol, and/or lithium; history of hyperthyroidism; positive anti-thyrotropin antibodies; previous partial or total thyroidectomy; known fetal anomaly; known thrombophilia; known infections and mola hydatidoses; chronic renal failure; uncontrolled hypertension; known placental abnormalities; uterine malformation; history of medical and metabolic complications such as heart disease or diabetes; and refusal of consent to data collection in line with Italian privacy laws.

\section{Setting and methods}

The patients were randomly divided into two groups. Patients in group A received L-Se-Met soft gel caps $83 \mathrm{mcg} /$ day, while those in group B received placebo (PLB) (Fig. 1). All patients were treated for the entire duration of pregnancy and for 6 months after delivery. Follow-up visits took place at $10 \pm 2$ weeks (T1), $36 \pm 2$ weeks (T2) of gestation and 6 months after delivery (postpartum, PP). Each visit comprised gestational, obstetrical, maternal, and fetal history; physical examination; thyroid hormones; TPOAb and $\mathrm{TgAb}$; serum selenium concentration; thyroid ultrasound (US); and the short form 12-item (SF12) questionnaire. Data were collected by the participating centers using electronic case report forms (eCRF) at the baseline and at follow-up visits.

\section{Laboratory investigations}

Serum samples were analyzed at a central laboratory. Serum TSH, FT3, FT4, and Ab titers were measured using a thirdgeneration electrochemiluminescence immunoassay (Abbott, Rome, Italy). The reference laboratory values were 0.35-4.94 mIU/L for TSH, $1.71-3.71 \mathrm{pg} / \mathrm{L}$ for FT3, and $0.7-1.48 \mathrm{ng} / \mathrm{dl}$ for FT4. TgAb were considered positive when above $4.11 \mathrm{IU} / \mathrm{L}$; TPOAb were considered positive when above $5.61 \mathrm{IU} / \mathrm{L}$.

Serum selenium concentration (Se) was determined by open-vessel acid digestion of small serum volumes $(200 \mu \mathrm{L})$ followed by atomic fluorescence spectroscopy (FullTech Instruments, Rome, Italy), according to a method demonstrated in a previous study published by our group [20].

\section{Thyroid ultrasound}

Thyroid ultrasound (US) was performed in each participating center using an ultrasound scanner with a $7.5 \mathrm{MHz}$ 
Fig. 1 Study flowchart. L-SeMet indicates L-

seleniomethionine; P.E., physical examination; thyroid $\mathrm{U}$. S., thyroid ultrasonography; SF12 questionnaire, Quality of life assessment using the Short Form-12 Health survey questionnaire

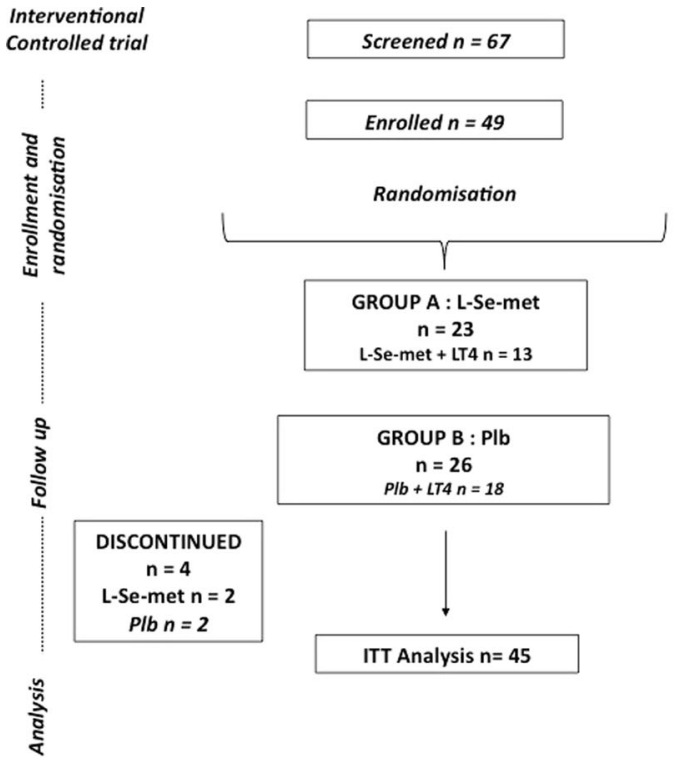

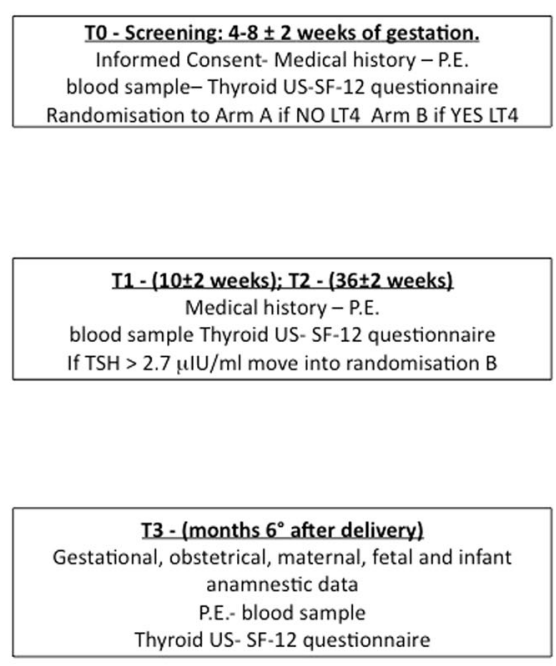

linear real-time transducer [21, 22]. The images were entered in the eCRF and analyzed by the coordinating center to calculate thyroid volume and to evaluate thyroid echogenicity.

Thyroid volume was computed measuring the maximum width, thickness, and length in both lobes of the thyroid gland. The lobes were approximated to ellipsoids and the maximum volume of each lobe was calculated using the formula: volume of one lobe $(\mathrm{mL})=$ length $(\mathrm{mm}) \times$ width $(\mathrm{mm}) \times$ depth $(\mathrm{mm}) \times 0.479$. The total thyroid volume was obtained by adding together the volumes of each lobe [23].

Constant operating conditions were defined for the measurement of thyroid echogenicity. The following parameters were adjusted before each US analysis: US power level (high), brightness gain $(30 \mathrm{~dB})$, depth range $(30-60 \mathrm{~dB}$, graduated), frame rate $(21 / \mathrm{min})$, B-mode dynamic range, B-mode enhancement level, and scan correlation. The US instrument settings were kept exactly the same for each patient at each follow-up visit to ensure that any differences in thyroid echogenicity reflected real changes in gland structure and not inter-assay variations. To compare thyroid echogenicity at each visit, all images were further analyzed offline using a widespread imaging analysis program available for download in the public domain (ImageJ, 1.49q, NIH, USA). Thyroid echogenicity was measured as described previously [11].

\section{SF12}

HRQOL was evaluated at each visit with the SF12 questionnaire. SF12 was developed in 1994 in English as a shorter alternative to the SF36 [24]. It consists of eight subscales, grouped into two scales: a physical component score (PCS) and a mental component score (MCS), in accordance with the SF12 guidelines. Both scores range between 0 and 100, with a higher score indicating better health [25].

\section{Statistical methods}

All data were entered in the eCRF and a database was created at the coordinating center. Statistical analysis was performed using SAS v. 9.4 (SAS Institute Inc., Cary, NC, USA). Normality of the continuous variables was tested with the Shapiro-Wilk test. Normally continuous variables were presented as mean $\pm \mathrm{SD}$, while those not normally distributed were presented as median (25th-75th percentile). The differences in the continuous variables between the two groups (Placebo vs. L-Se-Met) were tested by Student's $T$ test when data were normal or log-transformed and by Mann-Whitney $U$ test when data were not normally distributed. For dependent data the paired $T$ test was used when data were normally distributed or log-transformed, while Wilcoxon's test was used for non-normally distributed data. $p<0.05$ was considered to be statistically significant.

\section{Results}

Forty-five pregnant women with a mean age of $33.3 \pm 4.9$ years were enrolled. The mean BMI was 23.5 \pm 4.1 . Forty patients were nulliparous. At T1 32 patients were already taking LT4. Three patients started LT4 treatment. Ten patients required an LT4 dosage adjustment during pregnancy. After delivery, 10 patients reduced their LT4 dosage but no one stopped the therapy. There were no significant 
Table 1 Baseline characteristics of the 45 randomized subjects

\begin{tabular}{|c|c|c|c|}
\hline & $\begin{array}{l}\text { Group A } \\
\text { L-Se-Met } \\
n=21\end{array}$ & $\begin{array}{l}\text { Group B } \\
\text { PLB } \\
n=24\end{array}$ & $p$ Value \\
\hline Age (years) & $\begin{array}{l}32.2 \pm 4.9 \\
\text { mean } \pm \mathrm{SD}\end{array}$ & $\begin{array}{l}34.3 \pm 4.7 \\
\text { mean } \pm S D\end{array}$ & 0.21 \\
\hline BMI $\left(\mathrm{kg} / \mathrm{m}^{2}\right)$ & $\begin{array}{l}23.4 \pm 4.2 \\
\text { mean } \pm \mathrm{SD}\end{array}$ & $\begin{array}{l}23.6 \pm 4.2 \\
\text { mean } \pm \mathrm{SD}\end{array}$ & 0.51 \\
\hline $\begin{array}{l}\text { Systolic blood } \\
\text { pressure }(\mathrm{mmHg})\end{array}$ & $\begin{array}{l}100.00 \pm 14.83 \\
\text { mean } \pm \mathrm{SD}\end{array}$ & $\begin{array}{l}110.00 \pm 8.90 \\
\text { mean } \pm \mathrm{SD}\end{array}$ & 0.18 \\
\hline $\begin{array}{l}\text { Diastolic blood } \\
\text { pressure (mmHg) }\end{array}$ & $\begin{array}{l}62.50 \pm 7.41 \\
\text { mean } \pm S D\end{array}$ & $70.00 \pm 7.41$ & 0.89 \\
\hline Nulliparous (\%) & $20(66.7 \%)$ & $20(76.9 \%)$ & 0.41 \\
\hline Week of gestation & $\begin{array}{l}9.61 \pm 2.28 \\
\text { mean } \pm \mathrm{SD}\end{array}$ & $\begin{array}{l}10.09 \pm 2.91 \\
\text { mean } \pm \mathrm{SD}\end{array}$ & 0.85 \\
\hline TSH (mcIU/L) & $\begin{array}{l}1.77(0.90-2.48) \\
\text { median }(25 \text { th-75th } \\
\text { percentile) }\end{array}$ & $\begin{array}{l}1.21(0.68-1.82) \\
\text { median }(25 \text { th }-75 \text { th } \\
\text { percentile) }\end{array}$ & 0.42 \\
\hline FT3 (pg/mL) & $\begin{array}{l}2.85(2.56-3.09) \\
\text { median }(25 \text { th- } 75 \text { th } \\
\text { percentile) }\end{array}$ & $\begin{array}{l}2.81(2.59-3.09) \\
\text { median }(25 \text { th- } 75 \text { th } \\
\text { percentile) }\end{array}$ & 0.79 \\
\hline FT4 (ng/dL) & $\begin{array}{l}1.17 \pm 0.14 \\
\text { mean } \pm \mathrm{SD}\end{array}$ & $\begin{array}{l}1.07 \pm 0.14 \\
\text { mean } \pm \mathrm{SD}\end{array}$ & 0.86 \\
\hline AbTG (IU/mL) & $87.20 \pm 199.30$ & $54.36 \pm 66.66$ & 0.93 \\
\hline AbTPO (IU/mL) & $\begin{array}{l}159.00 \\
(50.21-570.00) \\
\text { median (25th-75th } \\
\text { percentile) }\end{array}$ & $\begin{array}{l}86.93 \\
(6.51-71.70) \\
\text { median (25th-75th } \\
\text { percentile) }\end{array}$ & 0.60 \\
\hline $\begin{array}{l}\text { Serum selenium } \\
\text { concentration }(\mathrm{mcg} / \mathrm{L})\end{array}$ & $\begin{array}{l}63.00 \\
(54.00-69.00) \\
\text { median (25th-75th } \\
\text { percentile) }\end{array}$ & $\begin{array}{l}66.00 \\
(54.00-78.00) \\
\text { median (25th-75th } \\
\text { percentile) }\end{array}$ & 0.63 \\
\hline
\end{tabular}

Normally continuous variables were presented as mean $\pm \mathrm{SD}$, while those not normally distributed were presented as median (25th-75th percentile)

differences between the L-Se-Met and PLB groups at T1 (Table 1).

\section{Autoantibody titer}

There were no significant differences in $\operatorname{TgAb}$ between the groups at T1 (L-Se-Met group 87.20 \pm 199.30 ; PLB group $54.36 \pm 66.66 ; p=0.93$ ) (Table 1). In both groups, $\mathrm{TgAb}$ values decreased significantly from $\mathrm{T} 1$ to $\mathrm{T} 2$ [L-Se-Met group T2 6.03 (2.82-27.67); $p<0.01 ;$ PLB group T2 $26.38 \pm 36.10 ; p=0.05]$. In the PLB group $\mathrm{TgAb}$ increased significantly from T2 to PP $(151.03 \pm 182.9 ; p<0.01)$, but in the L-Se-Met group it dropped significantly from baseline [19.86 (11.59-52.60); $p<0.01]$ (Table 2 and Fig. 2).

Regarding TPOAb values, there were no significant differences between the groups at T1 [L-Se-Met group 159.00 (50.21-570.00); PLB group 86.93 (6.51-71.70); $p=0.6$ ] (Table 1). TPOAb decreased significantly in both groups from $\mathrm{T} 1$ to $\mathrm{T} 2$ [L-Se-Met group 61.58 (20.10-148.75); $p=0.01$; PLB group 61.04 $\pm 70.91 ; p=$ 0.04]. In the PLB group TPOAb values increased significantly from T2 to PP $(441.28 \pm 512.18 ; p<0.01)$, while

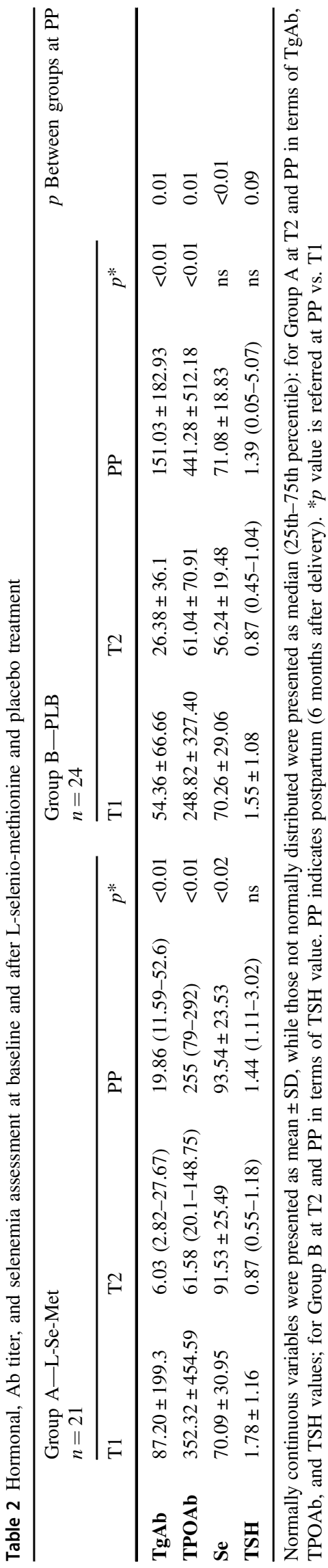




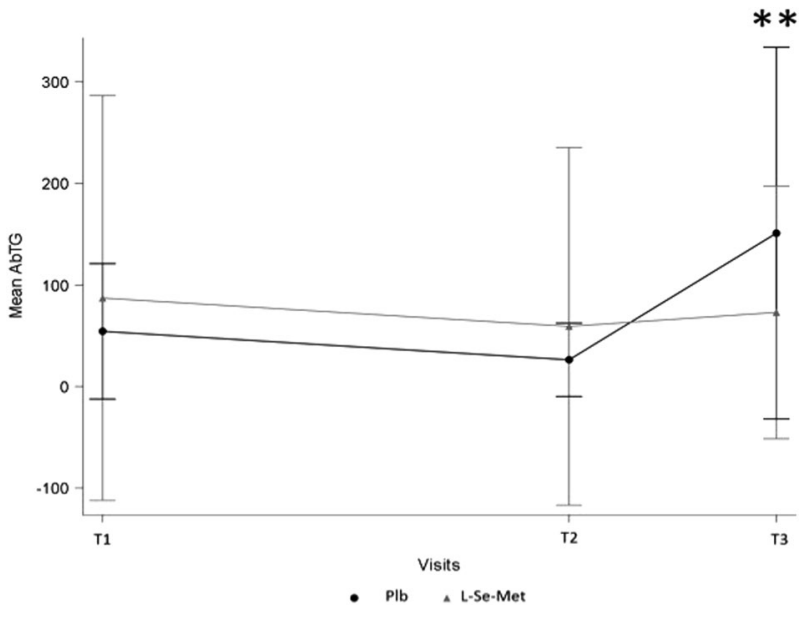

Fig. $2 \mathrm{TgAb}$ trends during and after pregnancy in L-Se-Met and PLB groups

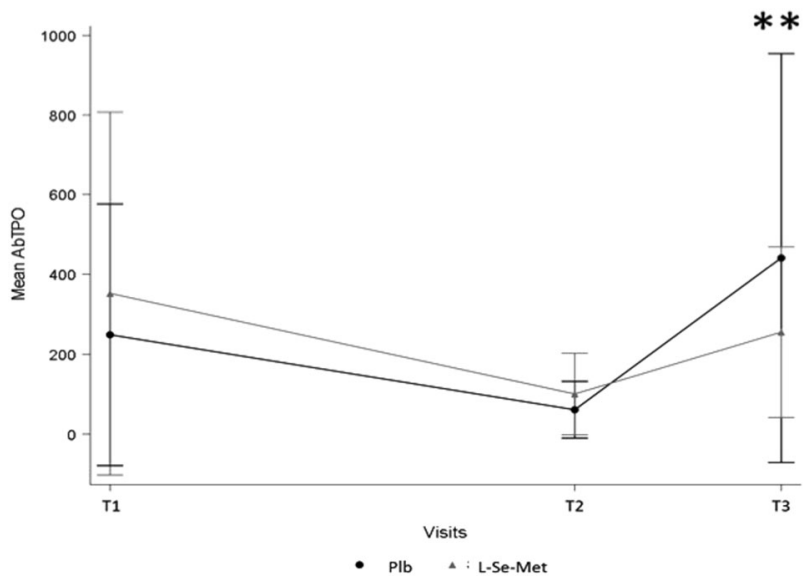

Fig. 3 TPOAb trends during and after pregnancy in L-Se-Met and PLB groups

in the L-Se-Met group they dropped significantly [255.00 (79.00-292.00); $p<0.01$ ] (Table 2 and Fig. 3).

\section{Thyroid function}

There were not significant differences in TSH values in both groups at T1 [L-Se-Met group: 1.77 (0.90-2.48); PLB group $1.21(0.68-1.82) ; p=0.42$ ] (Table 1) and decreased in both groups from T1 to T2 [L-Se-Met group T2 0.87 $(0.55-1.18) ; p=0.2$; PLB group T2 $0.87(0.45-1.04 ; p=$ $0.09]$. TSH values tended to increase in both groups from $\mathrm{T} 2$ to $\mathrm{PP}$ although the difference was not statistically significant [L-Se-Met group PP 1.44 (1.11-3.02); $p=0.2$; PLB group PP 1.39 (0.05-5.07); $p=0.04)]$ (Table 2). There were no statistically significant differences in FT3 and FT4 throughout pregnancy or at PP in either group.

\section{Serum selenium concentration}

No significant differences were measured in serum selenium concentration (Se) in both groups at T1 [L-Se-Met group: 63.00 (54.00-69.00); PLB group: 66.00 (54.00-78.00); $p=$ 0.63 ] (Table 1). In the PLB group Se decreased significantly from T1 to T2 (T2 $56.24 \pm 19.48 ; p<0.01$ ), subsequently increasing from T2 to PP (PP $71.08 \pm 18.83 ; p<0.01$ ). Se was significantly higher in the L-Se-Met group than in the PLB group at both T2 (L-Se-Met: $91.33 \pm 25.49$; PLB: $56.24 \pm 19.48 ; p<0.01)$ and PP (L-Se-Met: $93.55 \pm 23.53$; PLB: $71.08 \pm 18.83 ; p=0.02$ ) (Table 2).

\section{Thyroid US}

At $\mathrm{T} 1$, no significant differences were measured thyroid echogenicity (TE) in the two groups (L-Se-Met group 64.50 \pm 49.00; PLB group 47.80 $\pm 35.00 ; p=0.09)$. It did not change significantly in either group during pregnancy or by PP.

Thyroid volume was $8.15 \pm 5.09 \mathrm{~mL}$ in the PLB group and $6.14 \pm 2.35 \mathrm{~mL}$ in the L-Se-Met group; this difference was not statistically significant $(p=0.37)$. At T2 and PP, thyroid volume remained stable in both groups, again without any statistically significant inter-group difference (T2: $p=0.36$; T2: $p=0.54$ ).

\section{Health-related quality of life (HRQOL)}

No significant differences were measured in HRQOL for both groups (L-Se-Met group: $31.07 \pm 1.83$; PLB group: $30.67 \pm 2.40 ; p=0.61)$. SF12 did not vary significantly in either group at T2 $(p=0.98)$ or PP $(p=0.99)$.

\section{Maternal risk}

None of the women included in the study had a history of gestational diabetes, nor did they present gestational diabetes during the trial. We included among the adverse pregnancy outcomes the following: pre-eclampsia (gestational hypertension: systolic pressure $\geq 140 \mathrm{mmHg}$ or diastolic blood pressure $\geq 90 \mathrm{mmHg}$ [Korotkoff V] on $\geq 2$ occasions after 20 weeks gestation), miscarriage, placental abruption, abruption, gestational hypertension, gestational diabetes, breech presentation at birth, preterm birth ( $<37$ weeks gestation), symptomatic hypothyroidism, preterm labor, postpartum hemorrhage, postpartum depression, and maternal death.

\section{Discussion}

This multicenter, randomized, double-blind, placebocontrolled study evaluated the effects of L-Se-Met 
supplementation on antibody titer in euthyroid pregnant women with positive anti-thyroid antibodies. During pregnancy (from T0 to T2), TgAb and TPOAb decreased significantly in both groups, reflecting the general reduction in maternal immune response typical of this period to prevent rejection of the fetus. In contrast, at PP there was still a significant decrease in the L-Se-Met group but a significant increase in these antibodies in the PLB group.

Women who are thyroid $\mathrm{Ab}$ positive in the first trimester of pregnancy have a high risk of developing post-partum thyroiditis (PPT), with a prevalence ranging from 33 to $50 \%$ [26]. The higher the autoantibody titer, the higher the risk of developing PPT [27]. The clinical course of PPT can vary. Generally, hypothyroidism occurs from 3 to 12 months after delivery. A prospective study showed that $50 \%$ of women with PPT have permanent hypothyroidism at the end of the first postpartum year [28]. In 1990, Kampe et al. examined the influence of LT4 and iodide in preventing PPT, but neither intervention seemed to alter the course of PPT [29]. In 2007, Negro et al. evaluated the effect of Se-Met $200 \mathrm{mcg} /$ day administered during and after pregnancy on thyroid function, autoimmunity, and echogenicity patterns, finding that it reduced the incidence of PPT and hypothyroidism, reduced TPOAb titers, and ameliorated the US echogenicity pattern in comparison with controls [30]. However, in another recent randomized clinical trial 230 women with singleton pregnancies were randomized to receive $60 \mu \mathrm{g} /$ day selenium or placebo until delivery. Selenium supplementation was no more beneficial than placebo in reducing TPO-Ab concentration, though it tended to influence thyroid function in women with positive autoantibodies [31].

Furthermore, some studies evaluating non-pregnant women have shown that selenium can have an effect in reducing TPOAb concentrations [32-35]. Only one study, on 36 patients with autoimmune thyroiditis, found that sodium selenite ( $200 \mathrm{mcg}$ per day) administered for 3 months did not induce significant immunological changes (cytokine production patterns of peripheral $\mathrm{T}$ lymphocytes/ TPOAb levels).

Selenium supplementation seems to have an effect on thyroid function only in cases of selenium deficiency [36]. Two trials investigating selenium supplementation in a population of euthyroid women with autoimmune thyroiditis found that neither selenite nor selenomethionine had any effect on thyroid hormone concentrations [37, 38].

In our population, 32 patients $(71.1 \%)$ were taking LT4 at T1, 10 patients $(22.2 \%)$ required LT4 dosage adjustment during pregnancy, and three patients (6.7\%) began LT4 treatment between the 10th and the 20th week of gestation. LT4 treatment was started or adjusted to maintain TSH values below $2.7 \mathrm{mIU} / \mathrm{L}$, in accordance with current international guidelines [17, 39]. After delivery, 12 patients (26.7\%) reduced their LT4 dosage but no one stopped the therapy. Despite this, 6 months after delivery there was a clinically significant (albeit non-statistically significant) increase in TSH values in the PLB group.

This study used HG-AFS as a fast, new, and reliable technique to analyze selenium absorption and bioavailability, first validated in a previous study on 30 healthy volunteers published by our group. This method offers an economical way to quantify selenium and hence manage thyroid metabolism in various conditions for which L-SeMet supplementation is recommended, such as autoimmune thyroiditis and pregnancy [20]. We did not measure urine selenium given previous data showing low association between urine selenium changes and thyroid autoimmune activity during pregnancy [40].

The present study describes the pharmacokinetics properties of serum selenium concentration (Se) throughout pregnancy and at 6 months after delivery. The baseline Se in our sample was below the normal range. According to existing data, the optimal range should be considered as 80-120 mcg/L. Low Se has been associated with selenoprotein underactivity, especially of GPXs [16].

Subsequently, between $\mathrm{T} 1$ and $\mathrm{T} 2$ we observed an additional significant reduction in Se, followed in the PLB group by a significant increase at PP. This trend confirms the results of previous studies [30, 41, 42]. Nevertheless, low Se in pregnant women has in part been explained by the hemodilution typical of pregnancy [43]. However, the decline in Se during pregnancy should not be dismissed, because of the risk of developing severe selenium deficiency and pregnancy complications.

Thyroid echogenicity and volume during pregnancy were not influenced by L-Se-Met administration in our study. Two trials that investigated thyroid volume and echogenicity qualitatively found that $200 \mu \mathrm{g}$ of sodium selenite/day improved echogenicity after 3 and 9 months $[32,44]$. These data were confirmed in a quantitative analysis by Nacamulli et al., who reported greater hypoechogenicity in controls, as compared to the intervention group, after 12 months of $80 \mu \mathrm{g}$ sodium selenite/day [11].

To our knowledge, this is the first evaluation of the effects of L-Se-Met supplementation on HRQOL in pregnancy using SF12. We did not observe any significant differences between the L-Se-Met and PLB groups at the baseline, during pregnancy or 6 months after delivery.

Two double-blinded trials using the SF-36 form found no significant changes in HRQOL following 6 or 12 months of selenium supplementation in patients not treated with LT4 [37, 38]. Two studies using the SF-12 form found a significant improvement in wellbeing after $200 \mu \mathrm{g} /$ day of sodium selenite for 3 months compared to placebo [32, 45]. A significant beneficial effect of selenium administration on HRQOL was also demonstrated in a randomized, doubleblind, placebo-controlled trial comparing $200 \mathrm{mcg} /$ day 
sodium selenite to $1200 \mathrm{mg} /$ day pentoxifylline or placebo for 6 months in 159 patients with mild Graves' orbitopathy [46].

\section{Conclusions}

The SERENA study demonstrated that selenium supplementation at a dosage of $83 \mathrm{mcg} /$ day during pregnancy and after delivery is safe and has a beneficial effect on autoantibody titer and on postpartum thyroiditis recurrence. Selenium supplementation during pregnancy did not affect thyroid hormones, thyroid ultrasound, or HRQOL. No differences were found in adverse pregnancy outcomes.

Acknowledgements This paper has been registered by A.M.I. in the www.clinicaltrials.gov database with the ID NCT01465867. The authors would like to thank Marie-Hélène Hayles for revision of the English text.

Author contributions E. Giannetta, A.M.I. and A.L. designed the study and coordinated the multicentric study. G.M., A.M.I., C.M., E. Greco, P. C., M.B., A.F., L.P. and G.V. enrolled and followed patients. S.D.S., C. D.D. and C.P. performed quality control checks and separately analyzed thyroid US images. G.C. performed statistical analysis of the data. A.L. verified the analytic method and supervised the planned randomized double-blind placebo-controlled trial. E. Giannetta, A.M.I., C.D.D. and C.P. contributed to the final version of the manuscript.

\section{Compliance with ethical standards}

Conflict of interest The authors declare that they have no conflict of interest.

Ethical approval All procedures performed in studies involving human participants were in accordance with the ethical standards of the institutional and/or national research committee and with the 1964 Helsinki declaration and its later amendments or comparable ethical standards.

Publisher's note: Springer Nature remains neutral with regard to jurisdictional claims in published maps and institutional affiliations.

Open Access This article is distributed under the terms of the Creative Commons Attribution 4.0 International License (http://crea tivecommons.org/licenses/by/4.0/), which permits unrestricted use, distribution, and reproduction in any medium, provided you give appropriate credit to the original author(s) and the source, provide a link to the Creative Commons license, and indicate if changes were made.

\section{References}

1. A. Stagnaro-Green, S.H. Roman, R.H. Cobin, E. el-Harazy, M. Alvarez-Marfany, T.F. Davies, Detection of at-risk pregnancy by means of highly sensitive assays for thyroid autoantibodies. JAMA 264(11), 1422-1425 (1990)

2. A. Revelli, S. Casano, L.D. Piane, G. Grassi, G. Gennarelli, D. Guidetti, M. Massobrio, A retrospective study on IVF outcome in euthyroid patients with anti-thyroid antibodies: effects of levothyroxine, acetyl-salicylic acid and prednisolone adjuvant treatments. Reprod. Biol. Endocrinol. 7, 137 (2009). https://doi. org/10.1186/1477-7827-7-137

3. R. Negro, A. Schwartz, R. Gismondi, A. Tinelli, T. Mangieri, A. Stagnaro-Green, Thyroid antibody positivity in the first trimester of pregnancy is associated with negative pregnancy outcomes. J. Clin. Endocrinol. Metab. 96(6), E920-E924 (2011). https://doi. org/10.1210/jc.2011-0026

4. R. Negro, A. Stagnaro-Green, Thyroid autoantibodies, preterm birth, and miscarriage. BMJ 342, d2260 (2011). https://doi.org/10. 1136/bmj.d2260

5. Z. Tong, Z. Xiaowen, C. Baomin, L. Aihua, Z. Yingying, T. Weiping, S. Zhongyan, The effect of subclinical maternal thyroid dysfunction and autoimmunity on intrauterine growth restriction: a systematic review and meta-analysis. Medicine 95(19), e3677 (2016). https://doi.org/10.1097/MD.0000000000003677

6. M.P. Rayman, E. Searle, L. Kelly, S. Johnsen, K. Bodman-Smith, S.C. Bath, J. Mao, C.W. Redman, Effect of selenium on markers of risk of pre-eclampsia in UK pregnant women: a randomised, controlled pilot trial. Br. J. Nutr. 112(1), 99-111 (2014). https:// doi.org/10.1017/S0007114514000531

7. Y. Han, L.J. Mao, X. Ge, K. Huang, S.Q. Yan, L.L. Ren, S.Q. Hong, H. Gao, J. Sheng, Y.Y. Xu, W.J. Pan, P. Zhu, J.H. Hao, D. F. Zhu, F.B. Tao, Impact of maternal thyroid autoantibodies positivity on the risk of early term birth: Ma'anshan Birth Cohort Study. Endocrine 60(2), 329-338 (2018). https://doi.org/10.1007/ s12020-018-1576-6

8. A. Quintino-Moro, D.E. Zantut-Wittmann, M. Tambascia, C. Machado Hda, A. Fernandes, High prevalence of infertility among women with Graves' disease and Hashimoto's thyroiditis. Int J. Endocrinol. 2014, 982705 (2014). https://doi.org/10.1155/2014/ 982705

9. R. Negro, G. Formoso, T. Mangieri, A. Pezzarossa, D. Dazzi, H. Hassan, Levothyroxine treatment in euthyroid pregnant women with autoimmune thyroid disease: effects on obstetrical complications. J. Clin. Endocrinol. Metab. 91(7), 2587-2591 (2006). https://doi.org/10.1210/jc.2005-1603

10. R. Negro, A. Schwartz, A. Stagnaro-Green, Impact of levothyroxine in miscarriage and preterm delivery rates in first trimester thyroid antibody-positive women with TSH less than $2.5 \mathrm{mIU} / \mathrm{L}$. J. Clin. Endocrinol. Metab. 101(10), 3685-3690 (2016). https:// doi.org/10.1210/jc.2016-1803

11. D. Nacamulli, C. Mian, D. Petricca, F. Lazzarotto, S. Barollo, D. Pozza, S. Masiero, D. Faggian, M. Plebani, M.E. Girelli, F. Mantero, C. Betterle, Influence of physiological dietary selenium supplementation on the natural course of autoimmune thyroiditis. Clin. Endocrinol. 73(4), 535-539 (2010). https://doi.org/10.1111/ j.1365-2265.2009.03758.x

12. A.S. Al-Kunani, R. Knight, S.J. Haswell, J.W. Thompson, S.W. Lindow, The selenium status of women with a history of recurrent miscarriage. BJOG 108(10), 1094-1097 (2001)

13. Q. Wu, M.P. Rayman, H. Lv, L. Schomburg, B. Cui, C. Gao, P. Chen, G. Zhuang, Z. Zhang, X. Peng, H. Li, Y. Zhao, X. He, G. Zeng, F. Qin, P. Hou, B. Shi, Low population selenium status is associated with increased prevalence of thyroid disease. J. Clin. Endocrinol. Metab. 100(11), 4037-4047 (2015). https://doi.org/ 10.1210/jc.2015-2222

14. K.H. Winther, S.J. Bonnema, F. Cold, B. Debrabant, M. Nybo, S. Cold, L. Hegedus, Does selenium supplementation affect thyroid function? Results from a randomized, controlled, double-blinded trial in a Danish population. Eur. J. Endocrinol. 172(6), 657-667 (2015). https://doi.org/10.1530/EJE-15-0069

15. K.H. Winther, J.E. Wichman, S.J. Bonnema, L. Hegedus, Insufficient documentation for clinical efficacy of selenium supplementation in chronic autoimmune thyroiditis, based on a systematic review and meta-analysis. Endocrine 55(2), 376-385 (2017). https://doi.org/10.1007/s12020-016-1098-z 
16. L.H. Duntas, S. Benvenga, Selenium: an element for life. Endocrine 48(3), 756-775 (2015). https://doi.org/10.1007/s12020-014-04776

17. A. Stagnaro-Green, M. Abalovich, E. Alexander, F. Azizi, J. Mestman, R. Negro, A. Nixon, E.N. Pearce, O.P. Soldin, S. Sullivan, W. Wiersinga; American Thyroid Association Taskforce on Thyroid Disease During, Pregnancy and Postpartum, Guidelines of the American Thyroid Association for the diagnosis and management of thyroid disease during pregnancy and postpartum. Thyroid 21(10), 1081-1125 (2011). https://doi.org/10.1089/thy.2011.0087

18. G.A. Brent, Maternal thyroid function: interpretation of thyroid function tests in pregnancy. Clin. Obstet. Gynecol. 40(1), 3-15 (1997)

19. M. Abbassi-Ghanavati, L.G. Greer, F.G. Cunningham, Pregnancy and laboratory studies: a reference table for clinicians. Obstet. Gynecol. 114(6), 1326-1331 (2009). https://doi.org/10.1097/ AOG.0b013e3181c2bde8

20. C. Di Dato, D. Gianfrilli, E. Greco, M. Astolfi, S. Canepari, A. Lenzi, A.M. Isidori, E. Giannetta, Profiling of selenium absorption and accumulation in healthy subjects after prolonged Lselenomethionine supplementation. J. Endocrinol. Invest. 40(11), 1183-1190 (2017). https://doi.org/10.1007/s40618-017-0663-5

21. T. Rago, V. Cantisani, F. Ianni, L. Chiovato, R. Garberoglio, C. Durante, A. Frasoldati, S. Spiezia, R. Farina, G. Vallone, A. Pontecorvi, P. Vitti, Thyroid ultrasonography reporting: consensus of Italian Thyroid Association (AIT), Italian Society of Endocrinology (SIE), Italian Society of Ultrasonography in Medicine and Biology (SIUMB) and Ultrasound Chapter of Italian Society of Medical Radiology (SIRM). J. Endocrinol. Invest. 41(12), 1435-1443 (2018). https://doi.org/10.1007/s40618-018-0935-8

22. A.M. Isidori, V. Cantisani, E. Giannetta, D. Diacinti, E. David, V. Forte, D. Elia, C. De Vito, E. Sbardella, D. Gianfrilli, F. Monteleone, J. Pepe, S. Minisola, G. Ascenti, V. D’Andrea, C. Catalano, F. D'Ambrosio, Multiparametric ultrasonography and ultrasound elastography in the differentiation of parathyroid lesions from ectopic thyroid lesions or lymphadenopathies. Endocrine 57(2), 335-343 (2017). https://doi.org/10.1007/ s12020-016-1116-1

23. J. Brunn, U. Block, G. Ruf, I. Bos, W.P. Kunze, P.C. Scriba, [Volumetric analysis of thyroid lobes by real-time ultrasound (author's transl)]. Dtsch. Med. Woche. 106(41), 1338-1340 (1981). https://doi.org/10.1055/s-2008-1070506

24. B. Gandek, J.E. Ware, N.K. Aaronson, G. Apolone, J.B. Bjorner, J.E. Brazier, M. Bullinger, S. Kaasa, A. Leplege, L. Prieto, M. Sullivan, Cross-validation of item selection and scoring for the SF-12 Health Survey in nine countries: results from the IQOLA Project. International Quality of Life Assessment. J. Clin. Epidemiol. 51(11), 1171-1178 (1998)

25. C. Jenkinson, R. Layte, D. Jenkinson, K. Lawrence, S. Petersen, C. Paice, J. Stradling, A shorter form health survey: can the SF-12 replicate results from the SF-36 in longitudinal studies? J. Public Health Med. 19(2), 179-186 (1997)

26. W.K. Nicholson, K.A. Robinson, R.C. Smallridge, P.W. Ladenson, N.R. Powe, Prevalence of postpartum thyroid dysfunction: a quantitative review. Thyroid 16(6), 573-582 (2006). https://doi. org/10.1089/thy.2006.16.573

27. A. Stagnaro-Green, Approach to the patient with postpartum thyroiditis. J. Clin. Endocrinol. Metab. 97(2), 334-342 (2012). https://doi.org/10.1210/jc.2011-2576

28. A. Stagnaro-Green, A. Schwartz, R. Gismondi, A. Tinelli, T. Mangieri, R. Negro, High rate of persistent hypothyroidism in a large-scale prospective study of postpartum thyroiditis in southern Italy. J. Clin. Endocrinol. Metab. 96(3), 652-657 (2011). https:// doi.org/10.1210/jc.2010-1980

29. O. Kampe, R. Jansson, F.A. Karlsson, Effects of L-thyroxine and iodide on the development of autoimmune postpartum thyroiditis.
J. Clin. Endocrinol. Metab. 70(4), 1014-1018 (1990). https://doi. org/10.1210/jcem-70-4-1014

30. R. Negro, G. Greco, T. Mangieri, A. Pezzarossa, D. Dazzi, H. Hassan, The influence of selenium supplementation on postpartum thyroid status in pregnant women with thyroid peroxidase autoantibodies. J. Clin. Endocrinol. Metab. 92(4), 1263-1268 (2007). https://doi.org/10.1210/jc.2006-1821

31. J. Mao, V.J. Pop, S.C. Bath, H.L. Vader, C.W. Redman, M.P. Rayman, Effect of low-dose selenium on thyroid autoimmunity and thyroid function in UK pregnant women with mild-tomoderate iodine deficiency. Eur. J. Nutr. 55(1), 55-61 (2016). https://doi.org/10.1007/s00394-014-0822-9

32. R. Gartner, B.C. Gasnier, J.W. Dietrich, B. Krebs, M.W. Angstwurm, Selenium supplementation in patients with autoimmune thyroiditis decreases thyroid peroxidase antibodies concentrations. J. Clin. Endocrinol. Metab. 87(4), 1687-1691 (2002). https://doi. org/10.1210/jcem.87.4.8421

33. L.H. Duntas, E. Mantzou, D.A. Koutras, Effects of a six month treatment with selenomethionine in patients with autoimmune thyroiditis. Eur. J. Endocrinol. 148(4), 389-393 (2003)

34. E.E. Mazokopakis, J.A. Papadakis, M.G. Papadomanolaki, A.G. Batistakis, T.G. Giannakopoulos, E.E. Protopapadakis, E.S. Ganotakis, Effects of 12 months treatment with Lselenomethionine on serum anti-TPO Levels in Patients with Hashimoto's thyroiditis. Thyroid 17(7), 609-612 (2007). https:// doi.org/10.1089/thy.2007.0040

35. Y. Fan, S. Xu, H. Zhang, W. Cao, K. Wang, G. Chen, H. Di, M. Cao, C. Liu, Selenium supplementation for autoimmune thyroiditis: a systematic review and meta-analysis. Int J. Endocrinol. 2014, 904573 (2014). https://doi.org/10.1155/2014/904573

36. C.D. Thomson, S.K. McLachlan, A.M. Grant, E. Paterson, A.J. Lillico, The effect of selenium on thyroid status in a population with marginal selenium and iodine status. Br. J. Nutr. 94(6), 962-968 (2005)

37. T. Pilli, S. Cantara, L. Schomburg, V. Cenci, S. Cardinale, E.C. Heid, E.C. Kuhn, G. Cevenini, F. Sestini, C. Fioravanti, G. D'Hauw, F. Pacini, IFNgamma-inducible chemokines decrease upon selenomethionine supplementation in women with euthyroid autoimmune thyroiditis: comparison between two doses of selenomethionine ( 80 or $160 \mathrm{mug}$ ) versus placebo. Eur. Thyroid J. 4 (4), 226-233 (2015). https://doi.org/10.1159/000439589

38. S.A. Eskes, E. Endert, E. Fliers, E. Birnie, B. Hollenbach, L. Schomburg, J. Kohrle, W.M. Wiersinga, Selenite supplementation in euthyroid subjects with thyroid peroxidase antibodies. Clin. Endocrinol. 80(3), 444-451 (2014). https://doi.org/10.1111/cen.12284

39. L. De Groot, M. Abalovich, E.K. Alexander, N. Amino, L. Barbour, R.H. Cobin, C.J. Eastman, J.H. Lazarus, D. Luton, S.J. Mandel, J. Mestman, J. Rovet, S. Sullivan, Management of thyroid dysfunction during pregnancy and postpartum: an Endocrine Society clinical practice guideline. J. Clin. Endocrinol. Metab. 97 (8), 2543-2565 (2012). https://doi.org/10.1210/jc.2011-2803

40. E. Koukkou, I. Ilias, M. Alexiou, I. Mamali, S. Nicopoulou, M. Alevizaki, K. Markou, Urine selenium changes during pregnancy do not correlate with thyroid autoantibodies in a mildly iodine deficient population. Biol. Trace Elem. Res. 157(1), 9-13 (2014). https://doi.org/10.1007/s12011-013-9860-z

41. C.D. Thomson, M.A. Packer, J.A. Butler, A.J. Duffield, K.L. O'Donaghue, P.D. Whanger, Urinary selenium and iodine during pregnancy and lactation. J. Trace Elem. Med. Biol. 14(4), 210-217 (2001). https://doi.org/10.1016/S0946-672X(01)80004-3

42. M. Navarro, H. Lopez, V. Perez, M.C. Lopez, Serum selenium levels during normal pregnancy in healthy Spanish women. Sci. Total Environ. 186(3), 237-242 (1996)

43. E. Ferrer, A. Alegria, R. Barbera, R. Farre, M.J. Lagarda, J. Monleon, Whole blood selenium content in pregnant women. Sci. Total Environ. 227(2-3), 139-143 (1999) 
44. R. Gartner, B.C. Gasnier, Selenium in the treatment of autoimmune thyroiditis. Biofactors 19(3-4), 165-170 (2003)

45. G. Karanikas, M. Schuetz, S. Kontur, H. Duan, S. Kommata, R. Schoen, A. Antoni, K. Kletter, R. Dudczak, M. Willheim, No immunological benefit of selenium in consecutive patients with autoimmune thyroiditis. Thyroid 18(1), 7-12 (2008). https://doi. org/10.1089/thy.2007.0127
46. C. Marcocci, G.J. Kahaly, G.E. Krassas, L. Bartalena, M. Prummel, M. Stahl, M.A. Altea, M. Nardi, S. Pitz, K. Boboridis, P. Sivelli, G. von Arx, M.P. Mourits, L. Baldeschi, W. Bencivelli, W. Wiersinga,European Group on Graves' Orbitopathy, Selenium and the course of mild Graves' orbitopathy. N. Engl. J. Med. 364(20), 1920-1931 (2011). https://doi.org/10.1056/NEJMoa 1012985 